\title{
Nanoscale zero-valent iron-impregnated agricultural waste as an effective biosorbent for the removal of heavy metal ions from wastewater
}

\author{
P. Senthil Kumar ${ }^{*}$, A. Saravanan, P. Sundar rajan and M. Yashwanthraj
}

\begin{abstract}
A novel, nanoscale zero-valent iron-impregnated cashew nut shell (NZVI-CNS) was synthesized towards the removal of $\mathrm{Ni}(\mathrm{II})$ ions from aqueous solution using impregnation procedure. The factors affecting $\mathrm{Ni}(\mathrm{II})$ ion adsorption in a batch mode were studied including the initial metal ion concentration, solution pH, temperature, adsorbent dosage, and contact time. The adsorption isotherm and kinetics could be described well with Freundlich and pseudo firstorder, respectively. The maximum monolayer adsorption capacity for the removal of $\mathrm{Ni}(\mathrm{Il})$ ions was found to be $70.05 \mathrm{mg} / \mathrm{g}$. The calculated thermodynamic parameters showed that the removal of Ni(II) ions by the NZVI-CNS was spontaneous, feasible, and exothermic in nature. The amount of adsorbent needed to treat the known volume of the effluent was calculated by using single-stage batch adsorber design. The experimental results specifies that the NZVICNS have a high adsorption capacity for the removal of Ni(I) ions from aqueous solution.
\end{abstract}

Keywords: Adsorption, NZVI-CNS, Freundlich model, Pseudo first-order kinetics, Exothermic, Batch adsorber design

\section{Background}

In recent decades, industrialization and urbanization have grown exponentially to meet the human needs. As a result, the environmental impact has been increasing dramatically due to the direct discharge of toxic effluent into the water bodies. The toxic substances are mostly hazardous to human health which includes heavy metals, pharmaceuticals, pesticides, and dyes. Among which, heavy metals received a special attention by many researchers because they are persistent nature due to lack of biodegradability (Martins et al. 2013; Singh and Das 2013; Gong et al. 2013). In recent years, these heavy metals play a vital role in most of the industries. Particularly, nickel is widely used in diverse metal products and processes. Few of their applications are in industries such as electroplating, batteries manufacturing, mining, metal finishing, porcelain enameling, and paint formulations. The toxicity of nickel ions will cause severe health issues such as dermatitis, allergies, renal disturbances,

* Correspondence: senthilkumarp@ssn.edu.in

Department of Chemical Engineering, SSN College of Engineering, Chennai 603 110, India

\section{Springer}

(c) 2016 Kumar et al. Open Access This article is distributed under the terms of the Creative Commons Attribution 4.0 International License (http://creativecommons.org/licenses/by/4.0/), which permits unrestricted use, distribution, and reproduction in any medium, provided you give appropriate credit to the original author(s) and the source, provide a link to the Creative Commons license, and indicate if changes were made. hepatitis, infertility, lung cancer, stomatitis, gingivitis, insomnia, nauseas, and different poisoning degrees to the kidney and cardiovascular system (Paulino et al. 2007; $\mathrm{Fu}$ et al. 2015; Jeon and Cha 2015). Hence, the effluents with nickel ions should be treated before letting them into the receiving water bodies. According to the US EPA, the permissible limit of nickel in wastewater effluent is $2 \mathrm{mg} / \mathrm{L}$ for short-term effluent reuse and $0.2 \mathrm{mg} / \mathrm{L}$ for long-term effluent reuse (El-Sadaawy and Abdelwahab 2014; U.S EPA 2004). According to the Bureau of Indian Standards, the maximum permissible limit for $\mathrm{Ni}(\mathrm{II})$ ions in drinking water has been fixed at $0.02 \mathrm{mg} / \mathrm{L}$ (BIS 1994). Therefore, many technologies such as chemical precipitation (Purkayastha et al. 2014), ion exchange, electrochemical technologies (Fu and Wang 2011), adsorption (Bilal et al. 2013), and membrane filtration process such as microfiltration (Tashvigh et al. 2015), reverse osmosis (Wei et al. 2014), ultrafiltration (Tanhaei et al. 2014), nanofiltration (Alzahrani and Mohammad 2014), and electrodialysis (Dermentzis 2010) have been employed for both removal and recovery of $\mathrm{Ni}(\mathrm{II})$ ion from aqueous environment. Most of these technologies 
are expensive and incompatibility to remove the trace level of heavy metal ions. Among these technologies, many researchers focused on adsorption technology which offers simplicity, technical feasibility, economical viability, and social acceptability and also got high removal efficiency of heavy metal from aqueous solution. On the other hand, the main advantage of this process is reversible, because the adsorbents used for metal ions removal can be regenerated by employing appropriate desorption process (Barakat 2011; Zhou et al. 2015; Mahmoud et al. 2015). The commercial adsorbent such as activated carbons (Rajkumar et al. 2014), polymeric materials (Anitha et al. 2015), clays (Lee and Tiwari 2012), biosorbents (Kumar et al. 2015), and other adsorbents have been commonly used for this adsorption process. Many adsorbents usually have lower adsorption capacity, higher cost, longer equilibrium time, poor regeneration abilities, and separation problems (Prabu et al. 2015, 2016). Hence, adsorbents qualifying the aforementioned problems were synthesized and employed for removal of metal ions from aqueous environment.

Nanoscale zero-valent iron (NZVI) is a promising technology because many researchers focused on this process and implemented in the treatment of hazardous contaminants from wastewater. This increase in interest on the use of NZVI is owing to its higher surface area, lower cost, non-toxic, and higher reactivity (Uzum et al. 2009; Boparai et al. 2011; Arshadi et al. 2014; Prabu et al. 2016). The removal mechanism is directional transfer of electrons from NZVI to the contaminants and then the contaminant is transformed into non-toxic or less-toxic species. In addition, it also degrades and oxidize the organic compounds in the presence of dissolved oxygen (DO) ( $\mathrm{Fu}$ et al. 2014; Prabu et al. 2015, 2016). Mostly, direct of use of NZVI is restricted due to its lack of stability, easy aggregation, and facing difficulties in separating NZVI from treated effluents. To mitigate these issues, NZVI is impregnated with supporting material such as cashew nut shell (CNS) with the help of sonication operation. This does not only provide better operation but enhances the reduction ability of NZVI (Fu et al. 2014; Prabu et al. 2016). Finally, the efficient removal of nickel ions in aqueous environment can be achieved by utilizing the synthesized nanoscale zerovalent iron-impregnated cashew nut shell (NZVICNS). In this research, the batch adsorption studies for the removal of $\mathrm{Ni}(\mathrm{II})$ ions were investigated by using the several parameters such as initial $\mathrm{Ni}(\mathrm{II})$ concentration, solution $\mathrm{pH}$, temperature, adsorbent dose, and contact time. The adsorption isotherm, kinetics, design, and thermodynamic studies have been discussed to explain the adsorption process.

\section{Methods}

\section{Chemicals and equipment}

The chemical nickel(II) sulfate hexahydrate $\left[\mathrm{NiSO}_{4} \cdot 6 \mathrm{H}_{2} \mathrm{O}\right]$ was used to prepare the stock solution of $\mathrm{Ni}(\mathrm{II})$ ions. The nickel salt was taken in a measured amount and diluted in double distilled water. To make the desired $\mathrm{Ni}(\mathrm{II})$ ions concentration solution $(25-150 \mathrm{mg} / \mathrm{L})$, the stock solution was further diluted with distilled water. The $\mathrm{pH}$ of the different ion concentration solution was measured with a $\mathrm{pH}$ meter (Elico Limited, India) and was adjusted using $0.1 \mathrm{~N} \mathrm{NaOH}$ and $0.1 \mathrm{~N} \mathrm{HCL}$ solutions. The concentration of $\mathrm{Ni}(\mathrm{II})$ ions onto the ions solution before and after adsorption process was measured with an atomic adsorption spectrophotometer (AAS, SL 176 Model, Elico Limited, Chennai, India).

\section{Preparation of the adsorbent}

The adsorbent was prepared by simple liquid-phase reduction process, which is that NZVI was impregnated with the adsorbent material-CNS. One gram of CNS powder was washed with water to remove the impurities and then soaked in saturated $\mathrm{FeSO}_{4} \cdot 7 \mathrm{H}_{2} \mathrm{O}$ solution $(6.5 \mathrm{~g}$ in $25 \mathrm{~mL}$ with two drops of concentrated sulfuric acid) for $30 \mathrm{~min}$. After that, the soaked CNS along with the saturated $\mathrm{FeSO}_{4} \cdot 7 \mathrm{H}_{2} \mathrm{O}$ solution was continuously sonicated with the ultrasonic working frequency of $24 \mathrm{kHz}$ and mechanically agitated with the speed of $500 \mathrm{rpm} / \mathrm{min}$ for $60 \mathrm{~min}$. During the sonication process, the CNS particles were broken into small pieces under the thermodynamic condition. After the sonication, $0.1 \mathrm{~mol} / \mathrm{L} \mathrm{NaBH}_{4}$ was slowly added to the solution at optimum pressure, temperature, and atmosphere. Finally, the ferrous ion was impregnated into the CNS particles, and the ferrous ion was reduced to ZVI as per the -following reaction.

$$
\begin{aligned}
2 \mathrm{Fe}_{(\mathrm{aq})}^{2+} & +\mathrm{BH}_{4(\mathrm{aq})}^{-}+2 \mathrm{H}_{2} \mathrm{O}+\operatorname{support} \rightarrow \frac{2 \mathrm{Fe}^{\mathrm{o}}}{\operatorname{support}_{(\mathrm{s})}} \\
& +\mathrm{BO}_{2(\mathrm{aq})}^{-}+4 \mathrm{H}_{(\mathrm{aq})}^{+}+2 \mathrm{H}_{2}(\mathrm{~g}) .
\end{aligned}
$$

The CNS system was completely washed using distilled water followed by a wash with methanol to prevent the corrosion formation. At last, the CNS system was dried and stored in an oxygen-free nitrogen environment. This prepared material was abbreviated as NZVICNS (NZVI-impregnated CNS). During the synthesis of ZVI, the particles of boron were formed. These particles are toxic in nature, so special care must be needed for separating the boron particles.

\section{Batch adsorption studies}

The batch adsorption studies were performed to optimize the parameters such as initial $\mathrm{Ni}(\mathrm{II})$ concentration, 
solution $\mathrm{pH}$, temperature, adsorbent dose, and contact time on the effective removal of the $\mathrm{Ni}(\mathrm{II})$ ions from the aqueous solution using the NZVI-CNS. One hundred milliliters of the $\mathrm{Ni}(\mathrm{II})$ ion solution with varying concentrations $(25-150 \mathrm{mg} / \mathrm{L})$, adsorbent dosages $(0.5-3.0 \mathrm{~g} / \mathrm{L})$, solution $\mathrm{pH}(2.0-8.0)$, contact times (5-60 min), and temperatures $\left(30-60{ }^{\circ} \mathrm{C}\right)$ was taken in $100 \mathrm{~mL}$ Erlenmeyer flasks and then the mixture was kept in a temperaturecontrolled rotary shaker. The mixture was withdrawn at different time intervals $(0-60 \mathrm{~min})$. The concentration of the residual metal ions in the solutions was measured using an atomic adsorption spectrophotometer (AAS) (SL 176 Model, Elico Limited, Chennai, India). The percentage removal of the $\mathrm{Ni}(\mathrm{II})$ ion was calculated by using the following equation:

$$
\% \text { Removal of metal ions }=\frac{C_{\mathrm{o}}-C_{\mathrm{e}}}{C_{\mathrm{o}}} \times 100,
$$

where $C_{\mathrm{o}}(\mathrm{mg} / \mathrm{L})$ and $C_{\mathrm{e}}(\mathrm{mg} / \mathrm{L})$ are the initial and equilibrium concentrations of $\mathrm{Ni}(\mathrm{II})$ ion solution, respectively.

\section{Adsorption equilibrium experiments}

The adsorption isotherm studies were performed in a series of $100 \mathrm{~mL}$ Erlenmeyer flasks by adding $0.2 \mathrm{~g}$ of adsorbent material (NZVI-CNS) into $100 \mathrm{~mL}$ of the $\mathrm{Ni}(\mathrm{II})$ ion solution with the various initial $\mathrm{Ni}$ (II) ion concentrations in the range of 25 to $150 \mathrm{mg} / \mathrm{L}$ at an optimum condition, and then, the mixtures were kept in a temperature-controlled shaking incubator until its equilibrium time. Once the equilibrium time is reached, the flasks were withdrawn from the incubation shaker and the adsorbent material NZVI-CNS was centrifuged to separate the supernatant and the spent adsorbent. The concentration of $\mathrm{Ni}(\mathrm{II})$ ion in the supernatant was examined by using atomic adsorption spectrophotometer (AAS) (SL 176 Model, Elico Limited, Chennai, India), and the values are substituted in the following formula to know the amount of $\mathrm{Ni}$ (II) ion adsorbed onto the NZVI-CNS at equilibrium, $q_{\mathrm{e}}(\mathrm{mg} / \mathrm{g})$.

The amount of $\mathrm{Ni}(\mathrm{II})$ ions adsorbed at equilibrium $q_{\mathrm{e}}$ $(\mathrm{mg} / \mathrm{g})$

$$
q_{\mathrm{e}}=\frac{\left(C_{\mathrm{o}}-C_{\mathrm{e}}\right) V}{m}
$$

where $C_{\mathrm{o}}$ and $C_{\mathrm{e}}$ are the concentrations of $\mathrm{Ni}(\mathrm{II})$ ions in the solution initially and at equilibrium $(\mathrm{mg} / \mathrm{g})$, respectively, $V$ is the volume of the $\mathrm{Ni}(\mathrm{II})$ ion solution (L), and $m$ is the mass of the adsorbent (g).

The two-parameter and the three-parameter isotherm models were used to explain the $\mathrm{Ni}$ (II) ions adsorption towards the selected adsorbent. The different parameters,
$R^{2}$, and the error values are analyzed by the MATLAB R2009a software.

Langmuir (1918) and Freundlich (1906) are the twoparameter isotherm models used in this study.

The non-linear form of Langmuir adsorption isotherm model is as follows (Langmuir 1918):

$$
q_{\mathrm{e}}=\frac{q_{\mathrm{m}} K_{\mathrm{L}} C_{\mathrm{e}}}{1+K_{\mathrm{L}} C_{\mathrm{e}}},
$$

where $q_{\mathrm{e}}$ is the adsorption capacity at equilibrium $(\mathrm{mg} / \mathrm{g}), q_{\mathrm{m}}$ is the maximum monolayer adsorption capacity $(\mathrm{mg} / \mathrm{g}), C_{\mathrm{e}}$ is the concentration of the metal ions at equilibrium $(\mathrm{mg} / \mathrm{L})$, and $K_{\mathrm{L}}$ is the Langmuir equilibrium constant $(\mathrm{L} / \mathrm{mg})$.

The Freundlich adsorption model as follows (Freundlich 1906):

$$
q_{\mathrm{e}}=K_{\mathrm{F}} C_{\mathrm{e}}^{1 / \mathrm{n}},
$$

where $C_{\mathrm{e}}$ is the concentration of the metal ions at equilibrium $(\mathrm{mg} / \mathrm{L}), K_{\mathrm{F}}$ is the Freundlich constant $[(\mathrm{mg} /$ $\left.\mathrm{g})(\mathrm{L} / \mathrm{mg})^{(1 / n)}\right]$ related to the bonding energy, and $n$ is a measure of deviation from the linearity of adsorption (g/ L). The significance of " $n$ " is as follows: $n=1$ (linear), $n>1$ (physical process), and $n<1$ (chemical process).

Redlich and Peterson (1959) and Sips (1948) are the three-parameter isotherm models used in this study.

The Redlich-Peterson isotherm model is given as follows (Redlich and Peterson 1959):

$$
q_{\mathrm{e}}=\left(\frac{K_{\mathrm{RP}} C_{\mathrm{e}}}{1+\alpha_{\mathrm{RP}} C_{\mathrm{e}}^{\beta_{\mathrm{RP}}}}\right),
$$

where $C_{\mathrm{e}}$ is the concentration of metal ions at equilibrium $(\mathrm{mg} / \mathrm{L}), \beta_{\mathrm{RP}}$ is the exponent which lies between 0 and $1, K_{\mathrm{RP}}$ is the Redlich-Peterson isotherm constant (L/ $\mathrm{g}), \alpha_{\mathrm{RP}}$ is the Redlich-Peterson isotherm constant ( $\mathrm{L} /$ $\mathrm{mg})_{\mathrm{RP}}^{1 / \beta}$. The significance of $\beta$ is as given as follows: $\beta=1$ (Langmuir adsorption isotherm model is a preferable adsorption isotherm model) and $\beta=0$ (Freundlich adsorption isotherm model is a preferable adsorption isotherm model).

The Sips adsorption isotherm model is given as follows (Sips 1948):

$$
q_{\mathrm{e}}=\left(\frac{K_{\mathrm{S}} C_{\mathrm{e}}^{\beta_{\mathrm{s}}}}{1+\alpha_{\mathrm{S}} C_{\mathrm{e}}^{1 / \beta_{\mathrm{s}}}}\right),
$$

where $K_{\mathrm{s}}$ is the Sips model isotherm constant $(\mathrm{L} / \mathrm{g})^{\beta \mathrm{S}}$, $\alpha_{\mathrm{s}}$ is the Sips model constant $(\mathrm{L} / \mathrm{g})^{1 / \beta \mathrm{S}}$, and $\beta_{\mathrm{S}}$ is often regarded as the heterogeneity factor, with values close to 1 indicating a homogeneous binding site and values greater than 1 indicating a heterogeneous adsorption system. 


\section{Adsorption kinetic experiments}

The adsorption kinetic studies were performed in a series of $100 \mathrm{~mL}$ Erlenmeyer flasks by varying the contact time from 0 to $60 \mathrm{~min}$ of the adsorbent with the different initial $\mathrm{Ni}(\mathrm{II})$ ion solutions (25-150 mg/L) along with the adsorbents and kept in a temperaturecontrolled shaking incubation. At predetermined time intervals, the flasks were withdrawn from the incubation shaker, the adsorption mixture was centrifuged to separate the supernatant and the spent adsorbent. The concentration of $\mathrm{Ni}$ (II) ion in the supernatant was examined by using atomic adsorption spectrophotometer (AAS) (SL 176 Model, Elico Limited, Chennai, India), and the values are substituted in the following formula to know the amount of $\mathrm{Ni}(\mathrm{II})$ ion adsorbed onto the NZVI-CNS at different time intervals, $q_{\mathrm{t}}(\mathrm{mg} / \mathrm{g})$.

$$
q_{\mathrm{t}}=\frac{\left(C_{\mathrm{o}}-C_{\mathrm{t}}\right) V}{m}
$$

where $q_{\mathrm{t}}$ is the amount of $\mathrm{Ni}(\mathrm{II})$ ions adsorbed by the adsorbent at any time $(\mathrm{mg} / \mathrm{g}), C_{\mathrm{t}}$ is the concentration of $\mathrm{Ni}(\mathrm{II})$ ions at particular time $(\mathrm{mg} / \mathrm{L}), V$ is the volume of the metal ion solution (L), and $m$ is the mass of the adsorbent (g).

The pseudo first-order, pseudo second-order, and Elovich kinetic models are used to determine the rate of the adsorption process.

Pseudo first-order kinetic model is given as follows (Lagergren 1898):

$$
q_{\mathrm{t}}=q_{\mathrm{e}}\left(1-\exp \left(-k_{1} t\right)\right),
$$

where $q_{\mathrm{t}}$ is the adsorption capacity at any time $(\mathrm{mg} / \mathrm{g})$, $q_{\mathrm{e}}$ is the equilibrium adsorption capacity $(\mathrm{mg} / \mathrm{g}), k_{1}$ is the pseudo first-order kinetic rate constant $\left(\mathrm{min}^{-1}\right)$, and $t$ is the time ( $\mathrm{min}$ ).

Pseudo second-order kinetic model is given as follows (Ho and McKay 1999):

$$
q_{\mathrm{t}}=\frac{q_{\mathrm{e}}^{2} k_{2} t}{1+q_{\mathrm{e}} k_{2} t}
$$

where $k_{2}$ is the pseudo second-order kinetic rate constant ( $\mathrm{g} / \mathrm{mg} \mathrm{min})$ and $t$ is the time ( $\mathrm{min})$.

Elovich kinetic model is given as follows (Low 1960):

$$
q_{\mathrm{t}}=\left(1+\beta_{\mathrm{E}}\right) \ln \left(1+\alpha_{\mathrm{E}} \beta_{\mathrm{E}} t\right),
$$

where $\beta_{\mathrm{E}}$ is the desorption constant related to the activation energy of chemisorption $(\mathrm{g} / \mathrm{mg})$ and $\alpha_{\mathrm{E}}$ is the initial adsorption rate $(\mathrm{mg} /(\mathrm{g} \mathrm{min}))$.

\section{Adsorption thermodynamic study}

The adsorption thermodynamics studies were performed by varying the temperature of the batch adsorption system from 303 to $333 \mathrm{~K}$. The adsorption process is explained by the thermodynamic parameters like Gibbs free energy $\left(\Delta G^{\mathrm{o}}, \mathrm{kJ} \mathrm{mol}^{-1}\right)$, enthalpy $\left(\Delta H^{\mathrm{o}}, \mathrm{kJ} \mathrm{mol}^{-1}\right)$, and entropy $\left(\Delta S^{\mathrm{o}}, \mathrm{kJ} \mathrm{mol}^{-1}\right)$ which was calculated from the following equations:

$$
\begin{aligned}
& K_{c}=\frac{C_{\mathrm{Ae}}}{C_{\mathrm{e}}} \\
& \Delta G^{o}=-\mathrm{RT} \ln K_{\mathrm{c}} \\
& \Delta G^{\mathrm{o}}=\Delta H^{\mathrm{o}-T \Delta S^{\mathrm{o}}} \\
& \log K_{\mathrm{c}}=\frac{\Delta S^{\mathrm{o}}}{2.303 R}-\frac{\Delta H^{\mathrm{o}}}{2.303 R T},
\end{aligned}
$$

where $C_{\mathrm{Ae}}$ is the amount of $\mathrm{Ni}(\mathrm{II})$ ions adsorbed onto the adsorbent per liter of solution at equilibrium $(\mathrm{mg} / \mathrm{L})$, $C_{\mathrm{e}}$ is the equilibrium concentration in solution $(\mathrm{mg} / \mathrm{L}), T$ is the temperature $(\mathrm{K}), R$ is the gas constant $(8.314 \mathrm{~J} /$ $\mathrm{mol} / \mathrm{K})$, and $K_{\mathrm{c}}$ is the equilibrium constant. The values of $\Delta S^{\circ}$ and $\Delta H^{\circ}$ were calculated from the slope and the intercept of the plot of $\log K_{\mathrm{c}}$ versus $1 / T$.

\section{Results and discussions \\ Equilibrium studies \\ Influence of initial $\mathrm{Ni}(\mathrm{II})$ ion concentration on the adsorption of $\mathrm{Ni}(\mathrm{II})$ ions and adsorption isotherms}

The effect of initial $\mathrm{Ni}$ (II) ions concentration on the adsorption of $\mathrm{Ni}$ (II) ions is the main important parameter for resolving the adsorption capacity of the adsorbent. In this study, the effect of $\mathrm{Ni}(\mathrm{II})$ ion concentration was studied with the range of nickel ion concentration $=25-$ $150 \mathrm{mg} / \mathrm{L}$, solution $\mathrm{pH}=5.0$, adsorbent dose $=2 \mathrm{~g} / \mathrm{L}$, volume of sample $=100 \mathrm{~mL}$, equilibrium time $=30 \mathrm{~min}$, temperature $30{ }^{\circ} \mathrm{C}$, and the results were shown in Fig. 1. The experimental results showed that the percentage removal of $\mathrm{Ni}$ (II) ion was decreased from 99.72 to $87.89 \%$ with an increase in initial $\mathrm{Ni}$ (II) ion concentration from 25 to $150 \mathrm{mg} / \mathrm{L}$. Adsorption is a surface phenomenon,

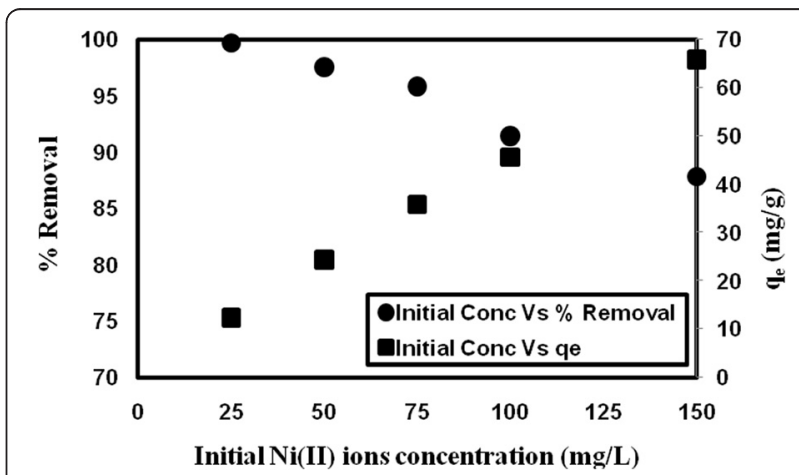

Fig. 1 Effect of initial $\mathrm{Ni}(\mathrm{II})$ ion concentration on the removal of $\mathrm{Ni}(\mathrm{II})$ ions by NZVI-CNS (nickel ion concentration $=25-150 \mathrm{mg} / \mathrm{L}$, solution $\mathrm{pH}=5.0$, adsorbent dose $=2 \mathrm{~g} / \mathrm{L}$, volume of sample $=100 \mathrm{~mL}$, equilibrium time $=30 \mathrm{~min}$, temperature $30^{\circ} \mathrm{C}$ ) 
the surface saturation of metal ions strongly depends on the initial metal ion concentrations. The initial concentration affords an essential driving force to conquer all mass transfer resistance of metal ions between the liquid phase and the solid phase. At low metal ion concentration, the availability of surface active sites might be high, i.e., the ratio of active sites to the metal ions in the aqueous solution is higher, therefore all the metal ions may be occupied on the active sites of the adsorbent ( $\mathrm{Li}$ et al. 2013). The drop off of removal percentage might be due to the saturation of available active sites at higher concentration. The adsorption capacity of NSZV-CNS was increased from 12.46 to $65.92 \mathrm{mg} / \mathrm{g}$, due to the higher adsorption rate and the exploitation of all available binding sites for adsorption at higher $\mathrm{Ni}(\mathrm{II})$ ion concentration.

The obtained equilibrium data from the effect of $\mathrm{Ni}(\mathrm{II})$ ion concentration studies were evaluated by using several adsorption isotherm model which can be used for the design of an adsorption system. In this study, Langmuir (Langmuir 1918), Freundlich (Freundlich 1906), Redlich-Peterson (Redlich and Peterson 1959), and Sips (Sips 1948) isotherm model were used to calculate the maximum monolayer adsorption capacity of NSZV$\mathrm{CNS}$ and the equilibrium data for the adsorption of $\mathrm{Ni}(\mathrm{II})$ ions from aqueous solution; the results were shown in Fig. 2. The Langmuir constant $\left(K_{\mathrm{L}}\right)$ and the monolayer adsorption capacity $\left(q_{\mathrm{m}}\right)$, the Freundlich isotherm constant $\left(K_{\mathrm{L}}\right)$ and $n$, the Redlich-Peterson isotherm constant $\left(K_{\mathrm{RP}}\right.$ and $\left.\alpha_{\mathrm{RP}}\right)$ and $\beta_{\mathrm{RB}}$ and the Sips model constant $\left(K_{\mathrm{S}}\right.$ and $\left.\alpha_{\mathrm{S}}\right)$ and $\beta_{\mathrm{S}}$ were determined using the plot $C_{\mathrm{e}}$ and $q_{\mathrm{e}}$. The adsorption isotherm parameters, determination of coefficient values $\left(R^{2}\right)$, and error values (sum of squared errors (SSE), root mean squared values (RMSE)) were attained by fitting the adsorption isotherm data to the adsorption isotherm models are shown in Table 1. As it can be seen in Table 1, Freundlich adsorption isotherm models have high correlation coefficient value $\left(R^{2}=0.9901\right)$ and low error values $(\mathrm{SSE}=27.77, \mathrm{RMSE}=2.635)$ compared to other isotherm

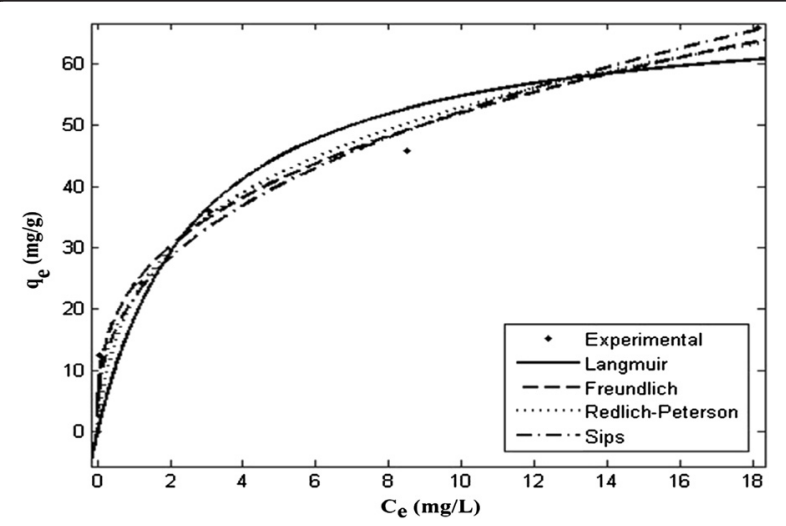

Fig. 2 Adsorption isotherm studies for the removal of $\mathrm{Ni}(\mathrm{II})$ ions by NZVI-CNS models. The adsorption isotherm data for the removal of $\mathrm{Ni}(\mathrm{II})$ ions onto the NSZV-CNS was constantly fitted with the Freundlich isotherm model which indicates that the adsorption process was the heterogeneous nature of active sites on the surface of the NSZV-CNS, a multilayer adsorption occurred between the adsorbent material NSZV$\mathrm{CNS}$ and the $\mathrm{Ni}(\mathrm{II})$ ions in the liquid solution (Jiang et al. 2012). The values of $n$ that were determined from the Freundlich isotherm model were found to be 2.956 for NSZV-CNS; the value of $n$ lies between 1 and 10, which indicates that the adsorption of $\mathrm{Ni}(\mathrm{II})$ ions onto the NSZV-CNS was physical adsorption. Based on the correlation coefficient values, the experimental data gave estimable fits within the following isotherm order: Freundlich > Sips $>$ Redlich-Peterson $>$ Langmuir.

\section{Influence of solution $\mathrm{pH}$ on the adsorption of $\mathrm{Ni}(\mathrm{II})$ ions}

The $\mathrm{pH}$ value of the aqueous solution plays a significant role in the adsorption process which affects the binding sites and chemical interaction between the metal ions and the adsorbents via changing the ionization state of the functional groups present on the surface of the adsorbent. In order to find out the optimum $\mathrm{pH}$, the effect of solution $\mathrm{pH}$ for the removal of $\mathrm{Ni}(\mathrm{II})$ ions by NZVICNS was deliberated over the range of solution $\mathrm{pH}=$ 2.0-8.0, adsorbent dose $=2 \mathrm{~g} / \mathrm{L}$, volume of sample $=$

Table 1 Isotherm constants of the two-parameter and threeparameter models for the removal of $\mathrm{Ni}(\mathrm{II})$ ions by NZVI-CNS

\begin{tabular}{|c|c|c|c|}
\hline & Parameters & Values & $R^{2}$ \\
\hline \multicolumn{4}{|l|}{ Two-parameter models } \\
\hline \multirow[t]{4}{*}{ Langmuir model } & $q_{\mathrm{m}}(\mathrm{mg} / \mathrm{g})$ & 70.05 & 0.9276 \\
\hline & $K_{\mathrm{L}}(\mathrm{L} / \mathrm{mg})$ & 0.3577 & \\
\hline & SSE & 203.4 & \\
\hline & RMSE & 7.131 & \\
\hline \multirow[t]{4}{*}{ Freundlich model } & $\left.K_{F}\left[(\mathrm{mg} / \mathrm{g})(\mathrm{L} / \mathrm{mg})^{(1 / n)}\right)\right]$ & 23.88 & 0.9901 \\
\hline & $n(g / L)$ & 2.956 & \\
\hline & SSE & 27.77 & \\
\hline & RMSE & 2.635 & \\
\hline \multicolumn{4}{|l|}{ Three-parameter models } \\
\hline \multirow[t]{5}{*}{ Redlich-Peterson model } & $K_{\mathrm{RP}}(\mathrm{L} / \mathrm{g})$ & 64.64 & 0.9613 \\
\hline & $a_{\mathrm{RP}}(\mathrm{L} / \mathrm{mg})^{(1 / \beta R P)}$ & 2.011 & \\
\hline & $\beta_{\mathrm{RP}}$ & 0.7487 & \\
\hline & SSE & 108.7 & \\
\hline & RMSE & 5.214 & \\
\hline \multirow[t]{5}{*}{ Sips model } & $K_{S}(L / g)^{\beta S}$ & 21.76 & 0.9848 \\
\hline & $a_{\mathrm{s}}(\mathrm{L} / \mathrm{mg})^{(\beta \mathrm{s})}$ & 1.798 & \\
\hline & $\beta_{S}$ & 0.3806 & \\
\hline & SSE & 40.31 & \\
\hline & RMSE & 3.174 & \\
\hline
\end{tabular}


$100 \mathrm{~mL}$, equilibrium time $=30 \mathrm{~min}$, temperature $30{ }^{\circ} \mathrm{C}$ with a nickel ions concentration $=25 \mathrm{mg} / \mathrm{L}$. Figure 3 shows that the percentage removal of $\mathrm{Ni}(\mathrm{II})$ ion was increased with the increase of $\mathrm{pH}$ value from 2.0 to 5.0. Beyond the $\mathrm{pH}$ value, the adsorption capacity remains constant due to the occurrence of hydroxyl ions which causes the arrangement of metal hydroxide complexes, which decline the adsorption capacity of NZVI-CNS. Figure 3 shows that the maximum removal of $\mathrm{Ni}$ (II) ions was attained at the solution $\mathrm{pH}$ of 5.0 which indicated that the adsorption capacity of NZVI-CNS was higher at acidic condition. At acidic condition due to the electrostatic interaction, the negatively charged $\mathrm{Ni}$ (II) ions was adsorbed by the positively charged adsorbent material NZVI-CNS.

\section{Influence of temperature on the adsorption of $\mathrm{Ni}(\mathrm{II})$ ions and thermodynamic studies}

The effect of temperature for the removal of $\mathrm{Ni}(\mathrm{II})$ ions onto the NZVI-CNS was studied by allowing the $\mathrm{Ni}$ (II) ion concentration $=25-150 \mathrm{mg} / \mathrm{L}$, solution $\mathrm{pH}=5.0$, adsorbent dose $=2 \mathrm{~g} / \mathrm{L}$, volume of sample $=100 \mathrm{~mL}$, equilibrium time $=30 \mathrm{~min}$, temperature $30-60{ }^{\circ} \mathrm{C}$, and the results were shown in Fig. 4. The results showed that the percentage removal of $\mathrm{Ni}$ (II) ions was decreased with an increase in the temperature from 30 to $60{ }^{\circ} \mathrm{C}$ for the $\mathrm{Ni}(\mathrm{II})$ ion concentration $(25-150 \mathrm{mg} / \mathrm{L})$, which indicates that the adsorption process was exothermic in nature. At higher temperature, the kinetic energies of $\mathrm{Ni}$ (II) ions was higher. Consequently, the adsorption of high energy metal ions is not easier compared with low energy ions. This is probably due to the fading of adsorptive forces between the metal ions and the binding sites on the surface of the adsorbent material-NZVI-CNS, which means that the adsorption process is inversely proportional to the temperature (Karami 2013). The thermodynamic behaviors of the adsorption of $\mathrm{Ni}$ (II) ions onto

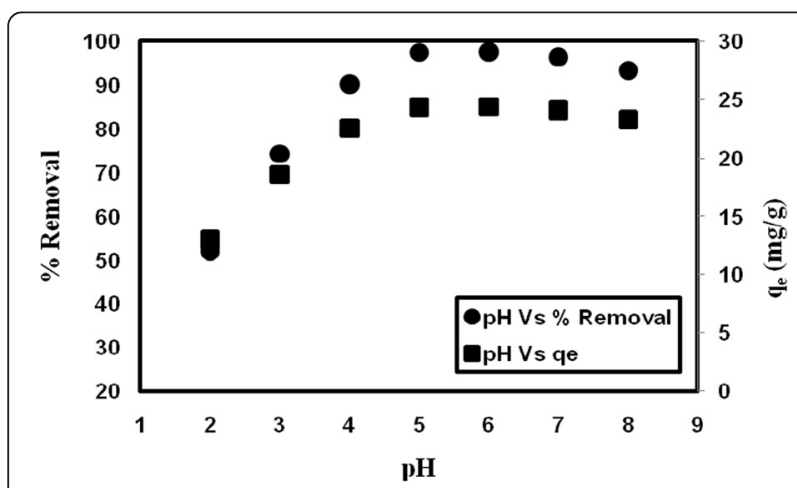

Fig. 3 Effect of solution $\mathrm{pH}$ for the removal of $\mathrm{Ni}(\mathrm{II})$ ions by NZVICNS (nickel ion concentration $=25 \mathrm{mg} / \mathrm{L}$, solution $\mathrm{pH}=2.0-8.0$, adsorbent dose $=2 \mathrm{~g} / \mathrm{L}$, volume of sample $=100 \mathrm{~mL}$, equilibrium time $=30 \mathrm{~min}$, temperature $30^{\circ} \mathrm{C}$ )

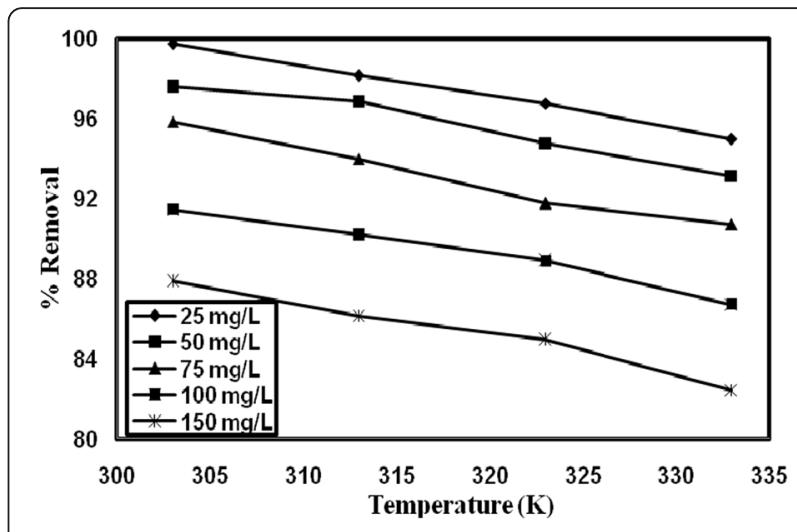

Fig. 4 Effect of temperature for the removal of $\mathrm{Ni}(\mathrm{II})$ ions by NZVICNS (nickel ion concentration $=25-150 \mathrm{mg} / \mathrm{L}$, solution $\mathrm{pH}=5.0$, adsorbent dose $=2 \mathrm{~g} / \mathrm{L}$, volume of sample $=100 \mathrm{~mL}$, equilibrium time $=30 \mathrm{~min}$, temperature $30-60{ }^{\circ} \mathrm{C}$ )

the NZVI-CNS were analyzed by plotting the graph between $\log K_{\mathrm{c}}$ and $1 / T$ (Fig. 5), and the calculated thermodynamic parameters such as Gibbs free energy $\left(\Delta G^{\mathrm{o}}\right)$, enthalpy change $\left(\Delta H^{\mathrm{o}}\right)$, and entropy change $\left(\Delta S^{\mathrm{o}}\right)$ for the adsorption of $\mathrm{Ni}$ (II) ions are shown in Table. 2. It was found that the negative value of Gibbs free energy was increased with an increase the temperature from 30 to $60{ }^{\circ} \mathrm{C}$ which confirms that the adsorption of $\mathrm{Ni}$ (II) ions onto the NZVI-CNS was more positive at low temperature and the adsorption process was feasible and spontaneous in nature ( $\mathrm{Li}$ et al. 2013). The negative value of changes in enthalpy $\left(\Delta H^{\circ}\right)$ confirm that the adsorption of $\mathrm{Ni}(\mathrm{II})$ ion onto the NZVI-CNS was exothermic in nature. The negative value of changes in entropy $\left(\Delta S^{\mathrm{o}}\right)$ indicated that the adsorption of $\mathrm{Ni}(\mathrm{II})$ ion onto the NZVI-CNS was enthalpy driven.

\section{Influence of adsorbent dosage on the adsorption of $\mathrm{Ni}(\mathrm{II})$ ions}

Temperature is the significant factor that can influence the adsorption process. The effect of temperature for the

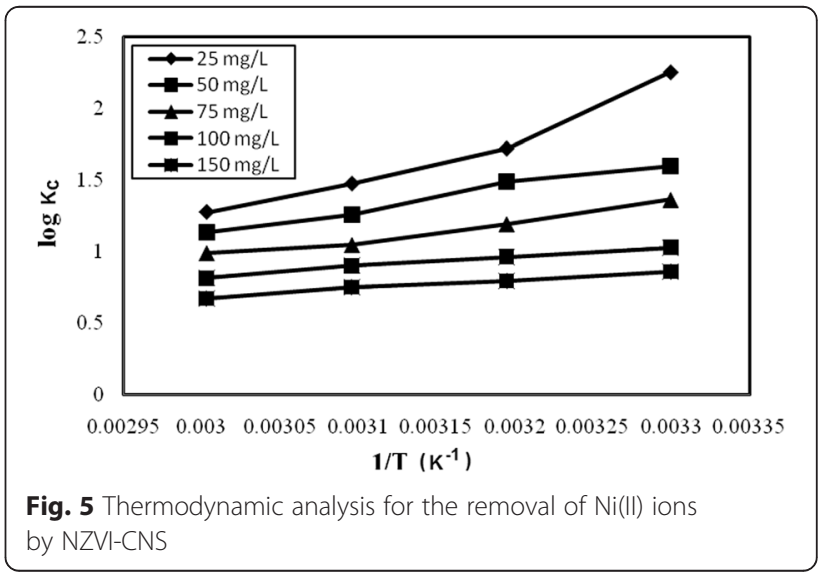


Table 2 Thermodynamic parameters for the adsorption of Ni(II) ions onto NZVI-CNS

\begin{tabular}{|c|c|c|c|c|c|c|c|}
\hline \multirow{2}{*}{$\begin{array}{l}\text { Metal } \\
\text { ions }\end{array}$} & \multirow{2}{*}{$\begin{array}{l}\text { Concentration } \\
\text { of } \mathrm{Ni}(\mathrm{II}) \text { ion } \\
\text { solution } \\
(\mathrm{mg} / \mathrm{L})\end{array}$} & \multirow{2}{*}{$\begin{array}{l}\Delta H^{\circ} \\
(\mathrm{kJ} / \mathrm{mol})\end{array}$} & \multirow{2}{*}{$\begin{array}{l}\Delta S^{\circ} \\
(\mathrm{J} / \mathrm{mol} / \mathrm{K})\end{array}$} & \multicolumn{4}{|c|}{$\Delta G^{\circ}(\mathrm{kJ} / \mathrm{mol})$} \\
\hline & & & & $30^{\circ} \mathrm{C}$ & $40^{\circ} \mathrm{C}$ & $50^{\circ} \mathrm{C}$ & $60^{\circ} \mathrm{C}$ \\
\hline \multirow[t]{5}{*}{$\overline{\mathrm{Ni}(I)}$} & 25 & -61.998 & -162.94 & -14.846 & -10.327 & -9.134 & -8.143 \\
\hline & 50 & -31.688 & -73.52 & -9.300 & -8.936 & -7.790 & -7.226 \\
\hline & 75 & -24.699 & -55.76 & -7.920 & -7.152 & -6.479 & -6.312 \\
\hline & 100 & -13.630 & -25.12 & -5.979 & -5.782 & -5.586 & -5.200 \\
\hline & 150 & -11.719 & -22.15 & -4.994 & -4.761 & -4.653 & -4.288 \\
\hline
\end{tabular}

removal of $\mathrm{Ni}(\mathrm{II})$ ion was studied by using the optimum parameters such as $\mathrm{Ni}(\mathrm{II})$ ion concentration $=25 \mathrm{mg} / \mathrm{L}$, solution $\mathrm{pH}=5.0$, volume of sample $=100 \mathrm{~mL}$, equilibrium time $=30 \mathrm{~min}$, temperature $30{ }^{\circ} \mathrm{C}$, and the varied adsorbent dosage of $0.5-3 \mathrm{~g} / \mathrm{L}$, and the results were shown in Fig. 6. From Fig. 6, it was observed at the percentage removal of $\mathrm{Ni}(\mathrm{II})$ ions was increased with an increase in the adsorbent dosage from 0.5 to $3 \mathrm{~g} / \mathrm{L}$. This may be possible due to the increase in available binding sites of the adsorbent with the increase in adsorbent dosage (Fan et al. 2008). The maximum percentage removal was attained at $2 \mathrm{~g} / \mathrm{L}$, beyond that the removal percentage was almost constant. The equilibrium adsorption capacity $\left(q_{\mathrm{e}}\right)$ was decreased with the increase in the adsorbent dosage. The reason for this may be due to the more availability of binding sites and increase in the surface area at lower adsorbent dose; therefore, the metal uptake capacity will be high at lower dosage. Conversely, overlying or aggregation of the adsorption sites at higher dosage (Lata et al. 2008).

\section{Influence of contact time on the adsorption of $\mathrm{Ni}(\mathrm{II})$ ions and kinetic studies}

The effect of contact time for the removal of $\mathrm{Ni}$ (II) ions onto the NZVI-CNS was studied with the range of $\mathrm{Ni}(\mathrm{II})$

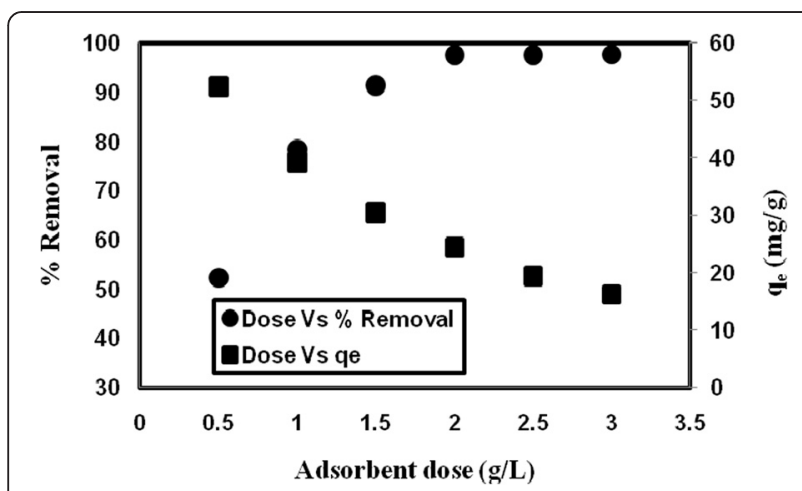

Fig. 6 Effect of adsorbent dose for the removal of $\mathrm{Ni}(\mathrm{II})$ ions by $\mathrm{NZVI-CNS}$ (nickel ion concentration $=25 \mathrm{mg} / \mathrm{L}$, solution $\mathrm{pH}=5.0$, adsorbent dose $=0.5-3 \mathrm{~g} / \mathrm{L}$, volume of sample $=100 \mathrm{~mL}$, equilibrium time $=30 \mathrm{~min}$, temperature $30^{\circ} \mathrm{C}$ ) ion concentration $=25-150 \mathrm{mg} / \mathrm{L}$, solution $\mathrm{pH}=5.0$, adsorbent dose $=2 \mathrm{~g} / \mathrm{L}$, volume of sample $=100 \mathrm{~mL}$, temperature $30{ }^{\circ} \mathrm{C}$, and contact time $=5-60 \mathrm{~min}$, and the results were shown in Fig. 7. From the Fig. 7, it was observed that the percentage removal of $\mathrm{Ni}$ (II) ion was increased with an increase in the contact time from 5 to $60 \mathrm{~min}$. The result affirmed that the percentage removal of $\mathrm{Ni}$ (II) ions onto the NZVI-CNS was increased quickly at the first $10 \mathrm{~min}$ and then increased gradually and reached adsorption equilibrium at $30 \mathrm{~min}$. The rapid increase of the adsorption of $\mathrm{Ni}$ (II) ions at the initial stage of contact time due to the accessibility of huge amount of binding sites on the surface of the adsorbent material. At lesser contact time, the residential time offered for the adsorption of $\mathrm{Ni}$ (II) ion onto the NZVI-CNS is less, for that reason, the percentage removal of $\mathrm{Ni}$ (II) ion is less. At higher contact time, the rate of adsorption slowly increased until equilibrium, this might be possibly due to the destabilization of driving force and the available binding sites were gradually tapered and taking long time to reach the adsorption equilibrium. The adsorption mechanism and the rate at which the $\mathrm{Ni}$ (II) ion was removed from the aqueous solution were estimated by using adsorption kinetic models. In these study, three kinetic models such as pseudo first-order (Lagergren

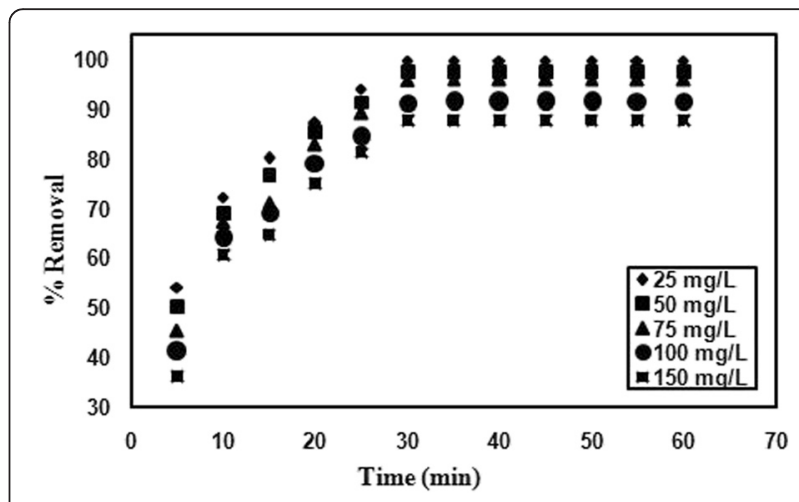

Fig. 7 Effect of contact time for the removal of $\mathrm{Ni}(\mathrm{II})$ ions by NZVICNS. Nickel ions concentration $=25-150 \mathrm{mg} / \mathrm{L}$, solution $\mathrm{pH}=5.0$, adsorbent dose $=2 \mathrm{~g} / \mathrm{L}$, volume of sample $=100 \mathrm{~mL}$, contact time $=$ 5-60 min, temperature $30^{\circ} \mathrm{C}$ 
1898), pseudo second-order (Ho and McKay 1999), and Elovich kinetic model (Low 1960) were used to examine the adsorption kinetics for the removal of $\mathrm{Ni}$ (II) ion onto the NZVI-CNS, and the results were shown in Fig. 8. The estimated parameters such as pseudo first-order kinetics constant $\left(k_{1}\right)$ and $q_{\mathrm{e}}$, the pseudo second-order kinetic constant $\left(k_{2}\right)$ and $q_{\mathrm{e}}$, and the Elovich kinetic model constant $\left(\alpha_{\mathrm{RP}}\right)$ and $\beta_{\mathrm{RP}}$ are listed in Table. 3. The comparison was made between the calculated adsorption capacity $\left(q_{\mathrm{e}}\right.$, cal $)$ and the experimental adsorption capacity $\left(q_{\mathrm{e}}\right.$, exp). It can be seen from Table 3 that the pseudo first-order kinetic were very closer to the experimental adsorption capacity value $\left(q_{\mathrm{e}}\right.$, exp) compared with other kinetic models. Additionally, the determination of correlation coefficient values for the pseudo first-order kinetic was higher compared with pseudo second-order and Elovich kinetic model. The adsorption kinetic data for the removal of $\mathrm{Ni}(\mathrm{II})$ ions onto the NSZV-CNS were constantly fitted with pseudo first-order kinetic model which indicates that the physical adsorption is the rate-determining step (Aliabadi et al. 2013). The prediction of the rate-limiting step is important to understand the adsorption mechanism. As it can be seen in Table 2 , the values of rate constant " $k$ " decreases as the concentration of $\mathrm{Ni}$ (II) ion increased; this might be possibly due to the lower competition for the binding sites at lower concentration. At higher


Fig. 8 Adsorption kinetic fit for the removal of Ni(II) ions by NZVI-CNS (nickel ion concentration $=25-150 \mathrm{mg} / \mathrm{L}$, solution $\mathrm{pH}=5.0$, adsorbent dose = $2 \mathrm{~g} / \mathrm{L}$, volume of sample $=100 \mathrm{~mL}$, temperature $=30^{\circ} \mathrm{C}$ ) 
Table 3 Adsorption kinetic data for the removal of Ni(II) ions by NZVI-CNS

\begin{tabular}{|c|c|c|c|c|c|c|}
\hline \multirow{2}{*}{$\begin{array}{l}\text { Adsorption kinetic } \\
\text { model }\end{array}$} & \multirow[t]{2}{*}{ Parameters } & \multicolumn{5}{|c|}{ Values (mg/L) } \\
\hline & & 25 & 50 & 75 & 100 & 150 \\
\hline \multirow[t]{6}{*}{ Pseudo first-order } & $q_{\mathrm{e}}(\mathrm{mg} / \mathrm{g})$ & 12.41 & 24.39 & 36.13 & 46.06 & 66.66 \\
\hline & $q_{\mathrm{e}}, \exp (\mathrm{mg} / \mathrm{g})$ & 12.47 & 24.49 & 36.14 & 45.95 & 65.99 \\
\hline & $k_{1}\left(\min ^{-1}\right)$ & 0.1305 & 0.1221 & 0.1105 & 0.1089 & 0.1019 \\
\hline & $R^{2}$ & 0.9941 & 0.9934 & 0.991 & 0.9935 & 0.9933 \\
\hline & SSE & 1.654 & 5.199 & 13.02 & 14.52 & 32.25 \\
\hline & RMSE & 0.3877 & 0.6875 & 1.088 & 1.149 & 1.712 \\
\hline \multirow[t]{5}{*}{ Pseudo second-order } & $q_{\mathrm{e}}, \mathrm{cal}(\mathrm{mg} / \mathrm{g})$ & 13.97 & 27.68 & 41.56 & 53.19 & 77.84 \\
\hline & $k_{2}(\mathrm{~g} / \mathrm{mg} \mathrm{min})$ & 0.0135 & 0.006159 & 0.00353 & 0.00267 & 0.00164 \\
\hline & $R^{2}$ & 0.9912 & 0.9907 & 0.99 & 0.9907 & 0.9871 \\
\hline & SSE & 0.9014 & 3.86 & 13.63 & 20.74 & 62.02 \\
\hline & RMSE & 0.2863 & 0.5924 & 1.113 & 1.373 & 2.374 \\
\hline \multirow[t]{5}{*}{ Elovich kinetic model } & $a_{E} \mathrm{mg} /(\mathrm{g} \min )$ & 1.478 & 2.958 & 0.272 & 0.181 & 0.2491 \\
\hline & $\beta_{\mathrm{E}}(\mathrm{g} / \mathrm{mg})$ & 0.5539 & 1.128 & 3.303 & 4.596 & 5.872 \\
\hline & $R^{2}$ & 0.9378 & 0.9793 & 0.962 & 0.9608 & 0.9679 \\
\hline & SSE & 9.666 & 12.59 & 51.87 & 87.75 & 154.1 \\
\hline & RMSE & 0.8975 & 1.07 & 2.079 & 2.704 & 3.742 \\
\hline
\end{tabular}

concentration, the competition for the binding sites will be high and accordingly lower adsorption rates are attained (Gao et al. 2013).

\section{Design of a single-stage batch adsorber}

The best fitted adsorption isotherm model was used to design the single-stage batch adsorber for the removal of $\mathrm{Ni}(\mathrm{II})$ ions from aqueous solution. A schematic diagram of a single-stage batch adsorber is shown in Fig. 9. The main objective of the adsorber was to estimate the amount of adsorbent needed for treating the known volume and concentration of $\mathrm{Ni}$ (II) ions from the aqueous solution at optimum condition. The mass balance for the single-stage batch adsorption system at equilibrium condition can be given as follows (at time $t=0$, $\left.q_{0}=0\right)$ :

$$
V\left(C_{\mathrm{o}}-C_{\mathrm{e}}\right)=M\left(q_{\mathrm{e}}-q_{\mathrm{o}}\right),
$$

where $M$ is the mass of the adsorbent $(\mathrm{g}), V$ is the volume of $\mathrm{Ni}(\mathrm{II})$ ion solution (L), $C_{\mathrm{o}}$ is the initial $\mathrm{Ni}$ (II) ion concentration $(\mathrm{mg} / \mathrm{L}), C_{\mathrm{e}}$ is the $\mathrm{Ni}(\mathrm{II})$ ion concentration at equilibrium $(\mathrm{mg} / \mathrm{L}), q_{\mathrm{e}}$ is the equilibrium adsorption capacity $(\mathrm{mg} / \mathrm{g})$, and $q_{\mathrm{o}}$ is the adsorption capacity at time $t=0(\mathrm{mg} / \mathrm{g})$. In this study, the fresh adsorbent was used for the adsorption system, therefore $q_{\mathrm{o}}=0$, rearranging Eq. 16 gave

$$
M=\frac{\left(C_{\mathrm{o}}-C_{\mathrm{e}}\right)}{q_{\mathrm{e}}} V .
$$

The Freundlich adsorption isotherm model was best fitted for the present adsorption system; this model was included in Eq. 17 and the equation can be written as

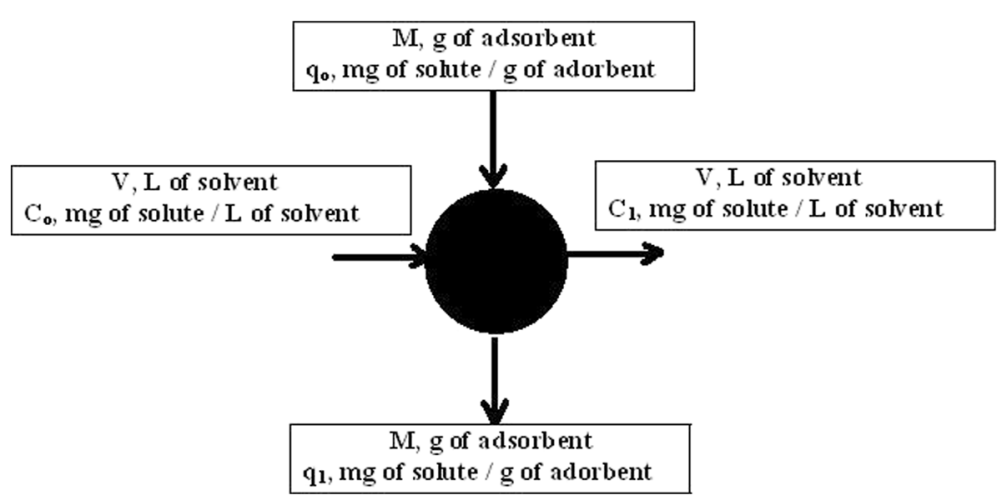

Fig. 9 Schematic diagram of a single-stage batch adsorber 


$$
M=\frac{\left(C_{\mathrm{o}}-C_{\mathrm{e}}\right)}{K_{\mathrm{F}} C_{\mathrm{e}}^{1 / n}} V
$$

Figure 10 shows the plot of mass of adsorbent versus volume of the solution of initial $\mathrm{Ni}(\mathrm{II})$ ion concentration of $75 \mathrm{mg} / \mathrm{L}$ for $75,80,58,90$, and $95 \%$ of $\mathrm{Ni}(\mathrm{II})$ ion removal at different solution volumes $(1-10 \mathrm{~L})$ for a single-stage batch adsorber. This design was used to calculate the amount of adsorbent dose needed for the treatment of known volume of the contaminated water. For example, the amount of optimum adsorbent dose needed to treat $10 \mathrm{~L}$ of the $\mathrm{Ni}(\mathrm{II})$ ion solution with $95 \%$ removal of $75 \mathrm{mg} / \mathrm{L} \mathrm{Ni(II)}$ ion solution was found to be $22.27 \mathrm{~g}$ of adsorbent.

\section{Conclusions}

In summary, we reported that the NZVI-CNS adsorbent material was successfully synthesized through the impregnated method which have been effectively used for the removal of $\mathrm{Ni}(\mathrm{II})$ ions from aqueous solution. The adsorption was studied kinetically using diverse adsorption kinetic models such as pseudo first-order, pseudo second-order, and Elovich kinetic models. The results showed that the adsorption process followed the pseudo first-order model based on higher correlation coefficient with low error values. The adsorption of $\mathrm{Ni}(\mathrm{II})$ ions onto NZVI-CNS was influenced by several operating parameters such as initial $\mathrm{Ni}(\mathrm{II})$ ion concentration, solution $\mathrm{pH}$, contact time, temperature, and adsorbent loading. The maximum monolayer adsorption capacity for the removal of $\mathrm{Ni}(\mathrm{II})$ ions was found to be $70.05 \mathrm{mg} / \mathrm{g}$ at an optimum condition. The equilibrium isotherm has been analyzed using different isotherm models such as Langmuir, Freundlich, Redlich-Peterson, and Sips model. Among these, the Freundlich isotherm model was identified as a well-suitable adsorption isotherm model based on the high coefficient of determination values with low error values. The adsorption thermodynamics illustrated

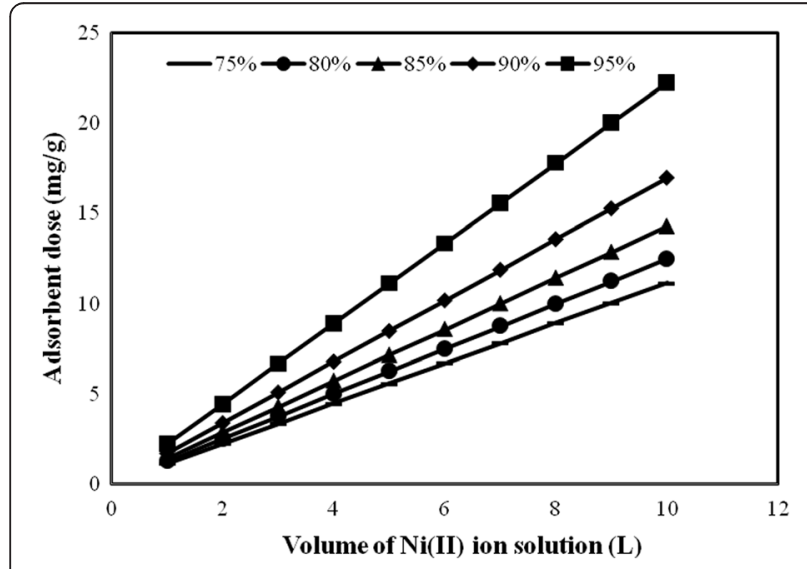

Fig. 10 Batch adsorber design for the removal of Ni(II) ions by NZVI-CNS that the electrostatic interaction plays an important role in the adsorption process. The values of thermodynamic parameters such as Gibbs free energy, entropy, and enthalpy indicated that the adsorption process was spontaneous, feasible, and exothermic in nature. A batch adsorber was designed to determine the amount of adsorbent dose needed for the treatment of a known volume of the desired $\mathrm{Ni}$ (II) ion concentration. Based on the experimental studies, it can be concluded that the NZVI-CNS materials has more potential for the removal of $\mathrm{Ni}$ (II) ions, and correspondingly for many other heavy metal ions from aqueous solution, with the advantages of being low cost, recyclable, efficient, and economically friendly.

\section{Competing interests}

The authors declare that they have no competing interests.

\section{Authors' contributions}

PSK have made substantial contributions to the conception and design, or acquisition of data, or analysis and interpretation of data and also have given final approval of the version to be published. AS, PSR, and MY have been involved in drafting the manuscript and revising it critically for important intellectual content. All authors read and approved the final manuscript.

Received: 16 December 2015 Accepted: 3 March 2016

Published online: 15 March 2016

\section{References}

Aliabadi, M., Irani, M., Ismaeili, J., Piri, H., \& Parnian, M. J. (2013). Electrospun nanofiber membrane of $\mathrm{PEO} /$ chitosan for the adsorption of nickel, cadmium, lead and copper ions from aqueous solution. Chemical Engineering Journal, $220,237-243$.

Alzahrani, S., \& Mohammad, A. W. (2014). Challenges and trends in membrane technology implementation for produced water treatment: a review. Journal of Water Process Engineering, 4, 107-133.

Anitha, T., Kumar, P. S., \& Kumar, S. (2015). Binding of Zn(II) ions to chitosan-PVA blend in aqueous environment: adsorption kinetics and equilibrium studies. Environmental Progress \& Sustainable Energy, 34, 15-22.

Arshadi, M., Soleymanzadeh, M., Salvacion, J. W. L., \& SalimiVahid, F. (2014). Nanoscale zero-valent iron (NZVI) supported on sineguelas waste for $\mathrm{Pb}(\mathrm{II})$ removal from aqueous solution: kinetics, thermodynamic and mechanism. Journal of Colloid and Interface Science, 426, 241-251.

Barakat, M. A. (2011). New trends in removing heavy metals from industrial wastewater. Arabian Journal of Chemistry, 4, 361-377.

Bilal, M., Shah, J. A., Ashfaq, T., Gardazi, S. M. H., Tahir, A. A., Pervez, A., Haroon, H., Mahmood, Q. (2013). Waste biomass adsorbents for copper removal from industrial wastewater-a review. Journal of Hazardous Materials, 263, 322-333.

BIS. (1994). Methods of sampling and test (physical and chemical) for water and waste water. Part 54 Nickel. IS No. 3025.

Boparai, K. H., Joseph, M., \& O'Carroll, D. M. (2011). Kinetics and thermodynamics of cadmium ion removal by adsorption onto nano zerovalent iron particles. Journal of Hazardous Materials, 186, 458-465.

Dermentzis, K. (2010). Removal of nickel from electroplating rinse waters using electrostatic shielding electrodialysis/electrodeionization. Journal of Hazardous Materials, 173, 647-652.

El-Sadaawy, M., \& Abdelwahab, O. (2014). Adsorptive removal of nickel from aqueous solutions by activated carbons from doum seed (Hyphaenethebaica) coat. Alexandria Engineering Journal, 53, 399-408.

Fan, T., Liu, Y. G., Feng, B. Y., Zeng, G. M., Yang, C. P., Zhou, M., Zhou, HZ., Tan, ZF. Wang, X. (2008). Biosorption of cadmium(II), zinc(II) and lead(II) by Penicillium simplicissimum: isotherms, kinetics and thermodynamics. Journal of Hazardous Materials, 160, 655-661.

Freundlich, H. M. F. (1906). Over the adsorption in solution. Journal of Physical Chemistry, 57, 385-470.

Fu, F., \& Wang, Q. (2011). Removal of heavy metal ions from wastewaters: a review. Journal of Environmental Management, 92, 407-418. 
Fu, F., Dionysiou, D. D., \& Liu, H. (2014). The use of zero-valent iron for groundwater remediation and wastewater treatment: a review. Journal of Hazardous Materials, 267, 194-205.

Fu, Y., Wu, J., Zhou, H., \& Jin, G. (2015). Removal of nickel(II) from aqueous solutions using iminodiacetic acid functionalized polyglycidyl methacrylate grafted-carbon fibers. Chinese Journal of Chemical Engineering, 23, 919-923.

Gao, J., Liu, F., Ling, P., Lei, J., Li, L., Li, C., Li, A. (2013). High efficient removal of $\mathrm{Cu}(\mathrm{II})$ by a chelating resin from strong acidic solutions: complex formation and DFT certification. Chemical Engineering Journal, 222, 240-247.

Gong, X., Li, W., Wang, K., \& Hu, J. (2013). Study of the adsorption of $\mathrm{Cr}(\mathrm{VI})$ by tannic acid immobilized powdered activated carbon from micro-polluted water in the presence of dissolved humic acid. Bioresource Technology, 141, $145-151$.

Ho, Y. S., \& McKay, G. (1999). Pseudo-second order kinetic model for sorption processes. Process Biochemistry, 34, 451-465.

Jeon, C., \& Cha, J. H. (2015). Removal of nickel ions from industrial wastewater using immobilized sericite beads. Journal of Industrial and Engineering Chemistry, 24, 107-112.

Jiang, N., Xu, Y., Dai, Y., Luo, W., \& Dai, L. (2012). Polyaniline nanofibers assembled alginate microsphere for $\mathrm{Cu}^{2+}$ and $\mathrm{Pb}^{2+}$ uptake. Journal of Hazardous Materials, 215-216, 17-24.

Karami, H. (2013). Heavy metal removal from water by magnetite nanorods. Chemical Engineering Journal, 219, 209-216.

Kumar, P.S., Pavithra, J., Suriya, S., Ramesh, M., Kumar, K.A. (2015). Sargassum wightii, a marine alga is the source for the production of algal oil, bio-oil, and application in the dye wastewater treatment. Desalination and Water Treatment, 55, 1342-1358.

Lagergren, S. (1898). About the theory of so-called adsorption of soluble substances. Kungliga Svenska Vetensk Handl, 24, 1-39.

Langmuir, I. (1918). The adsorption of gases on plane surfaces of glass, mica and platinum. Journal of American Chemical Society, 40, 1361-1368.

Lata, H., Garg, V., \& Gupta, R. (2008). Adsorptive removal of basic dye by chemically activated Parthenium biomass: equilibrium and kinetic modeling. Desalination, 219, 250-261.

Lee, S. M., \& Tiwari, D. (2012). Organo and inorgano-organo-modified clays in the remediation of aqueous solution: an overview. Applied Clay Science, 59-60, 84-102.

Li, X., Qi, Y., Li, Y., Zhang, Y., He, X., \& Wang, Y. (2013). Novel magnetic beads based on sodium alginate gel crosslinked by zirconium(IV) and their effective removal for $\mathrm{Pb}^{2+}$ in aqueous solutions by using a batch and continuous systems. Bioresource Technology, 142, 611-619.

Low, M. J. D. (1960). Kinetics of chemisorption of gases on solids. Chemical Reviews, 60, 267-312.

Mahmoud, A. M., Ibrahim, F. A., Shaban, S. A., \& Youssef, N. A. (2015). Adsorption of heavy metal ion from aqueous solution by nickel oxide nano catalyst prepared by different methods. Egyptian Journal of Petroleum, 24, 27-35.

Martins, A. E., Pereira, M. S., Jorgetto, O. A., Martines, M. A. U., Silva, R. I. V., Saeki, M. J., Castro, GR. (2013). The reactive surface of castor leaf [Ricinus communis L.] powder as a green adsorbent for the removal of heavy metals from natural river water. Applied Surface Science, 276, 24-30.

Paulino, A. T., Guilherme, M. R., Reis, A. V., Tambourgi, E. B., Nozaki, J., \& Muniz, E. C. (2007). Capacity of adsorption of $\mathrm{Pb}^{2+}$ and $\mathrm{Ni}^{2+}$ from aqueous solution by chitosan produced from silkworm chrysalides in different degrees of deacetylation. Journal of Hazardous Materials, 147, 139-147.

Prabu, D., Parthiban, R., Kumar, P. S., \& Namasivayam, S. K. R. (2015). Synthesis, characterization and antibacterial activity of nano zero-valent iron impregnated cashew nut shell. International Journal of Pharmacy and Pharmaceutical Science, 7, 139-141.

Prabu, D., Parthiban, R., Kumar, P.S., Kumari, N., Saikia, P. (2016). Adsorption of copper ions onto nano-scale zero-valent iron impregnated cashew nut shell. Desalination and Water Treatment, 57, 6487-6502.

Purkayastha, D., Mishra, U., \& Biswas, S. (2014). A comprehensive review on Cd(II) removal from aqueous solution. Journal of Water Process Engineering, 2, 105-128.

Rajkumar, P., Kumar, P. S., Priyadharshini, M., Kirupha, S. D., Baskaralingam, P., \& Sivanesan, S. (2014). Removal of $\mathrm{Cu}(\mathrm{II})$ ions from aqueous solution by adsorption onto activated carbon produced from Guazumaulmifolia seeds. Environmental Engineering and Management Journal, 13, 905-914.

Redlich, O., \& Peterson, D. L. (1959). A useful adsorption isotherms. Journal of Physical Chemistry, 63, 1024-1026.
Singh, B., \& Das, S. K. (2013). Adsorptive removal of Cu(II) from aqueous solution and industrial effluent using natural/agricultural wastes. Colloids and Surfaces B: Biointerfaces, 107, 97-106.

Sips, R. (1948). On the structure of a catalyst surface. Journal of Physical Chemistry, $16,490-495$

Tanhaei, B., Chenar, M. P., Saghatoleslami, N., Hesampour, M., Kallioinen, M., Sillanpaa, M., Manttari, M. (2014). Removal of nickel ions from aqueous solution by micellar-enhanced ultrafiltration, using mixed anionic-non-ionic surfactants. Separation and Purification Technology, 138, 169-176.

Tashvigh, A. A., Fouladitajar, A., \& Ashtiani, F. Z. (2015). Modeling concentration polarization in crossflow microfiltration of oil-in-water emulsion using shearinduced diffusion; CFD and experimental studies. Desalination, 357, 225-232.

U.S EPA. (2004). Guidelines for water reuse, EPA/625/R-04/108, U.S. Agency for Inter. Development, Washington, DC, USA.

Uzum, C., Shahwan, T., Eroglu, A. E., Hallam, K. R., Scott, T. B., \& Lieberwirth, I. (2009). Synthesis and characterization of kaolinite-supported zero-valent iron nanoparticles and their application for the removal of aqueous $\mathrm{Cu}^{2+}$ and $\mathrm{Co}^{2}$ ${ }^{+}$ions. Applied Clay Science, 43, 172-181.

Wei, X., Gu, P., \& Zhang, G. (2014). Reverse osmosis concentrate treatment by a PAC countercurrent four-stage adsorption/MF hybrid process. Desalination, $352,18-26$.

Zhou, G., Liu, C., Tang, Y., Luo, S., Zeng, Z., Liu, Y., Xu, R., Chu, L. (2015). Spongelike polysiloxane-graphene oxide gel as a highly efficient and renewable adsorbent for lead and cadmium metals removal form wastewater. Chemical Engineering Journal, 280, 275-282.

\section{Submit your manuscript to a SpringerOpen ${ }^{\circ}$ journal and benefit from:}

- Convenient online submission

- Rigorous peer review

- Immediate publication on acceptance

- Open access: articles freely available online

- High visibility within the field

- Retaining the copyright to your article

Submit your next manuscript at $>$ springeropen.com 